\title{
NO SISU, AS VAGAS DOS CURSOS DE ENGENHARIA RESERVADAS PARA PESSOAS COM DEFICIÊNCIA NÃO SÃO PREENCHIDAS. POR QUÊ?
}

DOI: 10.37702/2175-957X.COBENGE.2021.3657

Bruna Wendhausem Enne - brunawe@usp.br

Universidade de São Paulo

Rua Nossa Senhora de Lourdes 150

24360-420 - Niterói - RJ

Bruno Martin de Alcântara Dias - alcantara.dias@usp.br

Universidade de São Paulo

Rua Andradina 287

09060-460 - Santo André - SP

Osvaldo Shigueru Nakao - nakao@usp.br

USP

Alameda Jauaperi 1096

04523-014 - São Paulo - SP

Jose Aquiles Baesso Grimoni - jose.grimoni@usp.br

Universidade de Sao Paulo

Rua Pereira do Lago - 360158

05590-000 - Sao Paulo - SP

Resumo: A publicação da Lei no 12.711 completa dez anos em 2022. Conforme artigo 70 será promovida uma revisão do programa especial para o acesso de estudantes pretos, pardos, indígenas e com deficiência. Assim, o estudo da ociosidade das vagas destinadas às pessoas com deficiência possui caráter de urgência para a tomada de decisões durante a revisão da norma. $O$ presente artigo analisa os dados disponibilizados pelo SISU para o primeiro semestre de 2020, segundo semestre de 2020 e primeiro semestre de 2021, procurando estabelecer o perfil das vagas ociosas, focando nas possíveis causas para essa ociosidade com relação às vagas dos cursos de Engenharia reservadas para pessoas com deficiência no Ensino Superior. As vagas foram determinadas em função das características das populações dos estados, das regiões e do tipo de instituição. 
Relacionaram-se as vagas disponíveis e as vagas ociosas nos três semestres e tentou se estabelecer uma correlação entre o aumento da nota mínima do curso e o aumento da ociosidade da vaga, revelando que o percentual de ociosidade é proporcional à variação da nota mínima.

Palavras-chave: Engenharia; Cotas; Pessoa com Deficiência; Enem; Sisu 


\section{NO SISU, AS VAGAS DOS CURSOS DE ENGENHARIA RESERVADAS PARA PESSOAS COM DEFICIÊNCIA NÃO SÃO PREENCHIDAS. POR QUÊ?}

\section{INTRODUÇÃO}

O Exame Nacional do Ensino Médio - Enem criado inicialmente com o objetivo de aferir o domínio das competências e habilidades esperadas no final da educação básica, é hoje o principal mecanismo de acesso ao Ensino Superior no país (INEP, 2020c). Promovido anualmente pelo Instituto Nacional de Estudos e Pesquisas Educacionais Anísio Teixeira - INEP, o Enem ocorre em dois dias, avaliando os candidatos em Linguagens, Códigos e Redação, Ciências Humanas, Ciências da Natureza e Matemática (INEP, 2020a).

O oferecimento das vagas de instituições públicas de ensino superior é feito pelo Sistema de Seleção Unificada - SISU e os candidatos são selecionados de acordo com seu desempenho no Enem.

As vagas disponibilizadas no SISU obedecem à Lei no 12.711 de 2012 (BRASIL, 2012b), que dispõe sobre o ingresso nas universidades federais e é conhecida como "Lei das cotas". Determinou-se que, para cada concurso seletivo de ingresso na graduação, por curso e turno, seriam reservadas, no mínimo, $50 \%$ das vagas para estudantes que cursassem integralmente o ensino médio em escolas públicas. Dessa porcentagem, reserva-se metade para alunos com renda familiar igual ou inferior a 1,5 salários-mínimos per capita.

O artigo $3^{\circ}$ desta Lei refere-se à reserva de vagas para pessoas autodeclaradas pretas, pardas e indígenas e para pessoas com deficiência. A reserva de vagas é feita de acordo com a proporção de pretos, pardos, indígenas e pessoas com deficiência na população do estado onde está situada a Instituição de Ensino Superior. A proporção é obtida com resultados do último censo demográfico realizado pelo Instituto Brasileiro de Geografia e Estatística (IBGE, 2010) e sempre que o percentual implicar em um resultado com decimais, adota-se no arredondamento o número inteiro imediatamente superior (BRASIL, 2012a) e em cada curso deve assegurar, no mínimo, uma vaga.

De acordo com o Censo Demográfico promovido pelo IBGE em 2010, aproximadamente 45,6 milhões de pessoas possuíam pelo menos uma deficiência permanente (IBGE, 2010), ou seja, 24\% da população declarou possuir deficiência mental/intelectual ou certo grau de dificuldade em enxergar, ouvir, caminhar e subir degraus. Desse total ao considerar as pessoas que declararam possuir deficiência mental/intelectual ou grande ou total dificuldade em enxergar, ouvir, caminhar e subir degraus, há um total de 12,5 milhões de brasileiros com deficiência, o que corresponde a $6,7 \%$ da população.

Observou-se também que a deficiência visual estava presente em 3,4\% da população brasileira, enquanto a deficiência motora estava presente em $2,3 \%$ e a deficiência auditiva em 1,1\% e a deficiência mental/intelectual, sem o grau de dificuldade, somou $1,4 \%$ da população brasileira.

Em 2000, dois anos após a primeira edição do Enem, foi garantido pela primeira vez o atendimento especializado para pessoas com necessidades especiais, somando um total de 376 atendimentos, $0,1 \%$ do total de inscrições realizadas (INEP, 2020). Em 2019, 0 número de solicitantes de recursos de acessibilidade atingiu a marca de $1 \%$. Hoje, são disponibilizados pelo INEP, 15 recursos distintos para que as pessoas com deficiência 
realizem as provas com comodidade, desde apoio para os pés, mesas para usuários de cadeira de rodas, provas em Libras até provas impressas em Braile (JUNQUEIRA; MARTINS; LACERDA, 2017).

Essas medidas de inclusão vêm sendo acompanhadas e, segundo Esdras e Galasso (2017), a quantidade de instituições federais de ensino superior com alunos surdos, deficientes auditivos e surdo cegos quase dobrou de 2010 para 2015, de 50 para 92 instituições. Nesse mesmo intervalo de tempo, nas instituições estaduais de ensino também ocorreu um aumento de 31 para 49 instituições. A área mais procurada pelos alunos surdos nas instituições públicas de ensino superior é a Engenharia. Em 2015, havia 151 cursos com alunos surdos, $12 \%$ do total de matrículas.

No primeiro semestre de 2020, foram oferecidas pelo SISU 14.250 vagas para pessoas com deficiência em diversas instituições de ensino superior, federais e estaduais, cerca de $6 \%$ do total de vagas neste semestre. A porcentagem de vagas destinadas a cursos de Engenharia era 12\%. Ao analisar, no entanto, os dados disponíveis no site do sistema, percebe-se que $35 \%$ das vagas oferecidas ficaram ociosas. Isso significa que mais de um terço das vagas reservadas não foram ocupadas por pessoas com deficiência, sendo destinadas para outra categoria. No segundo semestre de 2020, esse cenário agudizou, com 3250 vagas disponíveis, mesmos $6 \%$ com relação ao total de vagas, e $42 \%$ não foram preenchidas (SISU, 2020).

O objetivo do estudo é analisar documentos disponibilizados pelo SISU para o primeiro semestre de 2020, segundo semestre de 2020 e primeiro semestre de 2021 e estabelecer o perfil das vagas ociosas, focando nas possíveis causas para essa ociosidade com relação às vagas dos cursos de Engenharia reservadas para pessoas com deficiência no Ensino Superior. Inclusive, estabelecendo uma relação entre o aumento da nota mínima do curso e o aumento da ociosidade da vaga, se existente.

\section{REFERENCIAL TEÓRICO}

A Lei no 12.711 promulgada no ano de 2012 em seu artigo 3ำ não previa vagas reservadas para pessoas com deficiência. Foi só em 2016, com a Lei nํ⒔406 (BRASIL, 2016), que o termo passou a constar, conforme segue:

Art. 3: Em cada instituição federal de ensino superior, as vagas de que trata o art. $1^{\circ}$ desta Lei serão preenchidas, por curso e turno, por autodeclarados pretos, pardos e indígenas e por pessoas com deficiência, nos termos da legislação, em proporção ao total de vagas no mínimo igual à proporção respectiva de pretos, pardos, indígenas e pessoas com deficiência na população da unidade da Federação onde está instalada a instituição, segundo o último censo da Fundação Instituto Brasileiro de Geografia e Estatística - IBGE. (Redação dada pela Lei no 13.409, de 2016) (BRASIL, 2012b, grifo nosso).

Essa alteração foi muito provavelmente estimulada pela promulgação da Lei Brasileira de Inclusão da Pessoa com Deficiência, Lei no 13.146, em julho de 2015, pois, em seu artigo 8으, fica claro o dever do Estado e da sociedade em assegurar à pessoa com deficiência, com prioridade, o direito à educação, à profissionalização e ao trabalho (BRASIL, 2015).

Logo, sempre que a proporção de pessoas com deficiência resultar em um número decimal, deve-se arredondar para o próximo número inteiro superior, assegurando-se, matematicamente, a obrigatoriedade de reserva de pelo menos uma vaga por curso e turno (BRASIL, 2012a). As instituições ainda podem adicionar vagas suplementares por meio de políticas específicas de ações afirmativas, além das exigidas no decreto. 
Caso a vaga reservada não seja ocupada naquela chamada, por vacância ou inelegibilidade, sua disponibilidade passa a ser contemplada por estudantes que tenham cursado integralmente 0 ensino médio em escolas públicas.

No contexto do Ensino Superior, a implementação da política de cotas visa corrigir um atraso com relação à educação das pessoas com deficiência (PEREIRA, 2020).

Por meio da mineração de microdados do SISU 2018, Oliveira, Barwald e Lucca (2020) determinaram a média final, média extraída pela soma das cinco áreas do conhecimento dividido por cinco, conforme indicado na Figura 1. É possível perceber que apenas $21 \%$ dos estudantes com deficiência conseguiram média superior a 620 neste ano.

Figura 1 - Notas dos alunos com deficiência no Enem 2018.

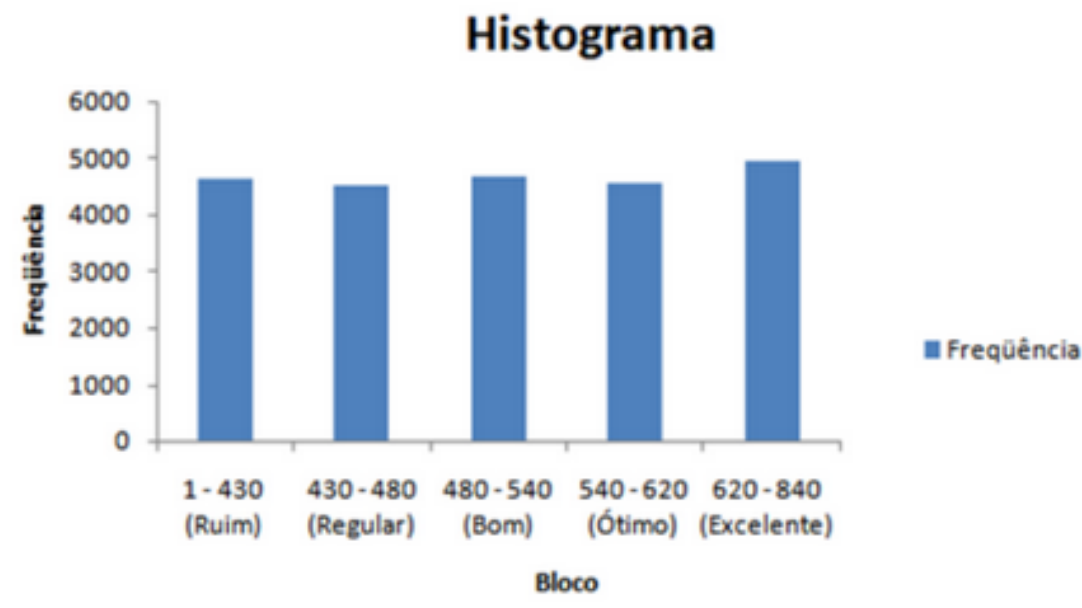

Fonte: Oliveira, Barwald e Lucca (2020), p. 5

Também no âmbito das notas, outro estudo de microdados do SISU por Leria et al. (2019) mostrou que pessoas com deficiência visual apresentaram notas médias $0,70 \%$ a $1,99 \%$ menores do que a média de pessoas sem deficiência em 2017 e 0,92\% a 5,03\% menores em 2018.

Com relação à distribuição de renda mensal dos estudantes, percebe-se que o desempenho final do candidato com deficiência é diretamente proporcional à sua renda. Tal resultado pode ser visto na Figura 2, que ilustra a proporção de renda em relação à média final, sendo R1 a menor renda e R5 equivalente à maior renda.

Figura 2 - Nota dos alunos com deficiência no Enem 2018 em função da renda.

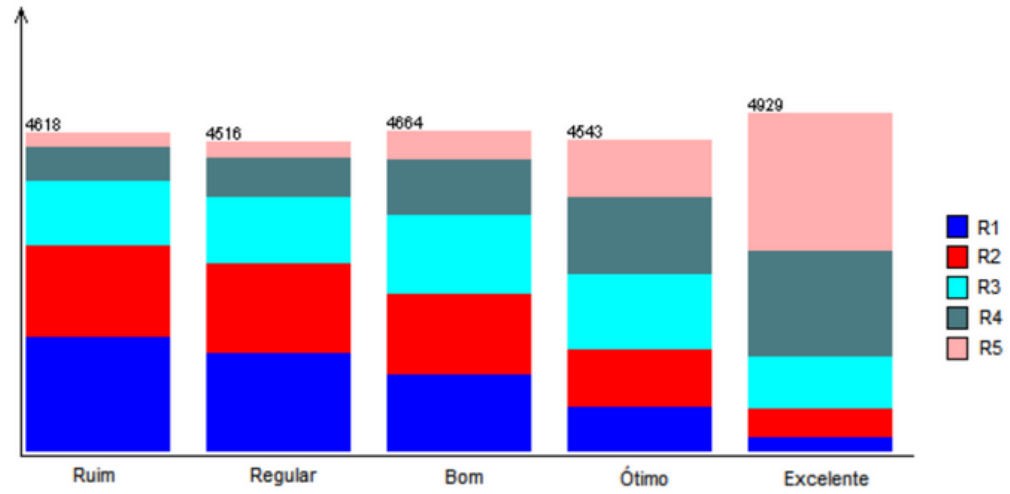

Fonte: Oliveira, Barwald e Lucca (2020), p. 9 


\section{METODOLOGIA}

Os dados utilizados na presente pesquisa foram extraídos do site do SISU. Para cada semestre foram disponibilizadas duas planilhas, intituladas "Vagas Ofertadas" e "Inscrições e Nota de Corte". No primeiro documento, foi possível extrair informações sobre a universidade (nome, sigla, código, localidade, tipo de instituição), sobre o curso oferecido (nome, código, campus, grau, turno, periodicidade, quantidade de semestres) e sobre a quantidade de vagas disponíveis naquele período (quantidade de vagas ofertada por categoria, nota mínima, pesos, percentual de reserva das vagas). Para fins da pesquisa, foram extraídos dessa planilha os dados referentes ao código do curso e às notas mínimas.

O segundo arquivo, "Inscrições e Nota de Corte", também continha as mesmas informações sobre a universidade e o curso, além da quantidade de vagas disponíveis (quantidade de vagas ofertada por categoria, nota de corte, quantidade de inscritos).

A nota mínima, descrita no primeiro documento, refere-se a um valor estipulado por cada curso, referente à nota mínima que um aluno deve alcançar para estar apto a se inscrever em um curso no SISU. Por outro lado, a nota de corte é uma medida gerada pelo próprio sistema, referente à nota do último aluno aprovado naquela categoria. A nota mínima interfere diretamente na ociosidade das vagas no SISU, pois impede a entrada de alunos no sistema. Por esse motivo, em 2021, a Universidade Federal do Rio Grande do Norte (UFRN), devido ao cenário precário da educação pública durante a pandemia devido à infecção pelo coronavírus ocorrida a partir de março de 2020, decidiu flexibilizar as notas mínimas de todas as provas para entrada na universidade. Tal medida visa preservar a política de inclusão, auxiliando na democratização do acesso de alunos da rede pública às instituições de ensino (UFRN, 2021).

As análises focaram em determinar um perfil da ociosidade de vagas para pessoas com deficiência nas três últimas edições do SISU, buscando encontrar um padrão a partir dos dados oferecidos nas planilhas.

\section{$4 \quad$ RESULTADOS}

Inicialmente, foi realizada uma filtragem nos dados no primeiro semestre de 2020 , no segundo semestre de 2020 e no primeiro semestre de 2021. A filtragem selecionou apenas os dados referentes aos cursos de engenharia no território nacional e que oferecessem vagas destinadas às pessoas com deficiência.

Assim, foi possível traçar o perfil das vagas para pessoas com deficiência disponíveis no Brasil por estado ou região. Adicionalmente, subtraindo as vagas disponíveis pelas vagas que foram preenchidas, obtêm-se as vagas ociosas. A Tabela 1 relaciona os estados, por sigla, à quantidade de vagas disponíveis e à quantidade de vagas não preenchidas para cada semestre do período estudado.

Tabela 1 - Vagas disponíveis e vagas ociosas por estado brasileiro nos períodos de 2020.1, 2020.2 e 2021.1

\begin{tabular}{|c|c|c|c|c|c|c|}
\hline Estado & $\begin{array}{c}\text { Vagas } \\
\text { disponíveis } \\
2020.1\end{array}$ & $\begin{array}{c}\text { Vagas } \\
\text { ociosas } \\
2020.1\end{array}$ & $\begin{array}{c}\text { Vagas } \\
\text { disponíveis } \\
2020.2\end{array}$ & $\begin{array}{c}\text { Vagas } \\
\text { ociosas } \\
2020.2\end{array}$ & $\begin{array}{c}\text { Vagas } \\
\text { disponíveis } \\
2021.1\end{array}$ & $\begin{array}{c}\text { Vagas } \\
\text { ociosas } \\
2021.1\end{array}$ \\
\hline $\mathrm{AC}$ & 39 & 20 & 15 & 2 & 39 & 28 \\
\hline $\mathrm{AL}$ & 44 & 12 & 6 & 1 & 30 & 9 \\
\hline
\end{tabular}




\begin{tabular}{|c|c|c|c|c|c|c|}
\hline AP & 13 & 0 & 0 & 0 & 0 & 0 \\
\hline AM & 8 & 0 & 0 & 0 & 0 & 0 \\
\hline $\mathrm{BA}$ & 124 & 30 & 40 & 15 & 120 & 39 \\
\hline CE & 159 & 35 & 73 & 28 & 116 & 27 \\
\hline $\mathrm{DF}$ & 0 & 0 & 0 & 0 & 0 & 0 \\
\hline ES & 86 & 35 & 22 & 12 & 76 & 39 \\
\hline GO & 92 & 27 & 0 & 0 & 72 & 46 \\
\hline$\overline{M A}$ & 16 & 0 & 10 & 1 & 14 & 1 \\
\hline MT & 67 & 35 & 0 & 0 & 67 & 48 \\
\hline MS & 16 & 9 & 8 & 0 & 16 & 5 \\
\hline MG & 377 & 158 & 68 & 31 & 349 & 207 \\
\hline$\overline{P A}$ & 51 & 1 & 0 & 0 & 49 & 3 \\
\hline PB & 181 & 72 & 47 & 22 & 181 & 110 \\
\hline PR & 126 & 65 & 110 & 76 & 115 & 75 \\
\hline $\mathrm{PE}$ & 166 & 68 & 0 & 0 & 170 & 96 \\
\hline $\mathrm{PI}$ & 66 & 20 & 62 & 34 & 73 & 41 \\
\hline RJ & 63 & 19 & 82 & 50 & 109 & 46 \\
\hline $\mathrm{RN}$ & 60 & 23 & 8 & 0 & 83 & 40 \\
\hline $\mathrm{RS}$ & 301 & 200 & 56 & 42 & 298 & 208 \\
\hline $\mathrm{RO}$ & 0 & 0 & 0 & 0 & 0 & 0 \\
\hline $\mathrm{RR}$ & 0 & 0 & 0 & 0 & 0 & 0 \\
\hline $\mathrm{SC}$ & 67 & 41 & 16 & 3 & 36 & 15 \\
\hline SP & 150 & 44 & 0 & 0 & 126 & 36 \\
\hline SE & 55 & 19 & 0 & 0 & 40 & 25 \\
\hline $\mathrm{TO}$ & 38 & 11 & 28 & 18 & 12 & 3 \\
\hline Total & 2.365 & 944 & 651 & 335 & 2.191 & 1.147 \\
\hline
\end{tabular}

A menor oferta de vagas em 2020.2 é prevista, porque no segundo semestre as universidades oferecem habitualmente menos vagas. O estado do Rio Grande do Sul, embora seja o estado a oferecer mais vagas, só conseguiu preencher $34 \%$ delas em $2020.1,25 \%$ em 2020.2 e $30 \%$ em 2021.1 .

Da mesma forma, a Tabela 2 indica a distribuição de vagas e sua ociosidade de forma distribuída pelas regiões do Brasil. 
Tabela 2 - Vagas disponíveis e vagas ociosas por região nos períodos de 2020.1, 2020.2 e 2021.1

\begin{tabular}{|c|c|c|c|c|c|c|}
\hline Região & $\begin{array}{c}\text { Vagas } \\
\text { disponíveis } \\
2020.1\end{array}$ & $\begin{array}{c}\text { Vagas } \\
\text { ociosas } \\
2020.1\end{array}$ & $\begin{array}{c}\text { Vagas } \\
\text { disponíveis } \\
2020.2\end{array}$ & $\begin{array}{c}\text { Vagas } \\
\text { ociosas } \\
2020.2\end{array}$ & $\begin{array}{c}\text { Vagas } \\
\text { disponíveis } \\
2021.1\end{array}$ & $\begin{array}{c}\text { Vagas } \\
\text { ociosas } \\
2021.1\end{array}$ \\
\hline Norte & 149 & 32 & 43 & 20 & 100 & 34 \\
\hline Nordeste & 871 & 279 & 246 & 101 & 827 & 388 \\
\hline Sul & 494 & 306 & 182 & 121 & 449 & 298 \\
\hline Sudeste & 676 & 256 & 172 & 93 & 660 & 328 \\
\hline Centro & 175 & 71 & 8 & 0 & 155 & 99 \\
\hline
\end{tabular}

A região Nordeste apresentou um número consideravelmente maior de vagas para os três semestres. Apenas $68 \%, 59 \%$ e $53 \%$ de suas vagas foram preenchidas, respectivamente, de acordo com o período estudado. A região Sudeste, em contrapartida, apresentou a taxa de ociosidade mais baixa entre todas as regiões.

Foi possível também extrair os mesmos dados referentes à disponibilidade de vagas de acordo com o tipo de instituição. Os dois tipos de instituição que ofereciam as vagas para pessoas com deficiência foram a instituição pública federal e a instituição pública estadual, sendo a oferta de vagas na universidade pública federal consideravelmente maior, como se vê na Tabela 3.

Tabela 3 - Vagas disponíveis e vagas ociosas por tipo de instituição nos períodos de 2020.1, 2020.2 e 2021.1

\begin{tabular}{|c|c|c|c|c|c|c|}
\hline $\begin{array}{c}\text { Tipo de } \\
\text { Instituição }\end{array}$ & $\begin{array}{c}\text { Vagas } \\
\text { disponíveis } \\
2020.1\end{array}$ & $\begin{array}{c}\text { Vagas } \\
\text { ociosas } \\
2020.1\end{array}$ & $\begin{array}{c}\text { Vagas } \\
\text { disponívei } \\
\text { s } 2020.2\end{array}$ & $\begin{array}{c}\text { Vagas } \\
\text { ociosas } \\
2020.2\end{array}$ & $\begin{array}{c}\text { Vagas } \\
\text { disponíveis } \\
2021.1\end{array}$ & $\begin{array}{c}\text { Vagas } \\
\text { ociosas } \\
2021.1\end{array}$ \\
\hline $\begin{array}{c}\text { Pública } \\
\text { Estadual }\end{array}$ & 107 & 28 & 8 & 0 & 63 & 10 \\
\hline $\begin{array}{c}\text { Pública } \\
\text { Federal }\end{array}$ & 2258 & 916 & 643 & 335 & 2.128 & 1.137 \\
\hline
\end{tabular}

A Tabela 4 explicita o total de vagas disponíveis, o total de vagas ociosas e a porcentagem de vagas ociosas em cada período. Percebe-se que nos dois últimos períodos, menos pessoas com deficiência ocuparam as vagas que lhes eram reservadas, embora o porcentual tenha se mantido. 
Tabela 4 - Vagas disponíveis e vagas ociosas totais nos períodos de 2020.1, 2020.2 e 2021.1

\begin{tabular}{|l|c|c|c|}
\hline & 2020.1 & 2020.2 & 2021.1 \\
\hline Disponível & 2.365 & 651 & 2.191 \\
\hline Ocioso & 944 & 335 & 1.147 \\
\hline $\begin{array}{l}\text { Porcentagem } \\
\text { de ociosidade }\end{array}$ & $39,9 \%$ & $52,4 \%$ & $52,3 \%$ \\
\hline
\end{tabular}

A Tabela 5 apresenta a porcentagem de ociosidade nos três períodos em função da nota mínima estipulada pelo curso. Essa nota mínima foi dada a partir da média das notas mínimas disponibilizadas no SISU para cada curso. Durante a pesquisa, foi possível perceber notas mínimas médias de 0 a 600, essa última muito alta quando se aplica a Teoria de Resposta ao Item (TRI), responsável por pontuar as questões do Enem. O TRI é uma modelagem estatística na qual as notas são atribuídas de acordo com a regularidade das respostas, evitando chutes ou fraudes (INEP, 2011). Em 2020, por exemplo, a maior nota da área de Linguagens foi por volta de 800, e não 1000.

Tabela 5 - Porcentagem de ociosidade em função do intervalo de nota mínima

\begin{tabular}{|l|c|c|c|}
\hline Média nota mínima & 2020.1 & 2020.2 & 2021.1 \\
\hline 0 a 200 & $18,4 \%$ & $50,4 \%$ & $22,3 \%$ \\
\hline 200 a 400 & $33,3 \%$ & $54,8 \%$ & $54,9 \%$ \\
\hline 400 a 600 & $65,8 \%$ & $85,3 \%$ & $71,6 \%$ \\
\hline
\end{tabular}

É possível perceber claramente que os cursos nos intervalos com notas mínimas mais altas apresentaram também as porcentagens de ociosidade mais altas para os três semestres. Logo, quanto maior a nota mínima, mais vagas reservadas não são preenchidas. Como o sistema do SISU não registra os estudantes que tentam se inscrever abaixo da nota mínima, não é possível saber quantas pessoas são eliminadas pelas notas mínimas estipuladas. Percebe-se, por fim, que entre os dois últimos intervalos, há uma discrepância de mais de $50 \%$ para todos os períodos estudados, atingindo $71,6 \%$ em 2021.1, ou seja, a ociosidade de cursos com nota no intervalo de 400 a 600 são cerca de $50 \%$ maiores que a ociosidade de cursos que atribuíram intervalo de nota mínima 200 a 400 .

\section{$5 \quad$ CONCLUSÕES}

Como será promovida em 2022 uma revisão do programa especial para o acesso de estudantes pretos, pardos, indígenas e com deficiência, há necessidade de se diagnosticar as razões da ociosidade nas vagas destinadas às pessoas com deficiência. Esses estudos 
possuem caráter de urgência para a tomada de decisões durante a revisão da norma, com embasamento científico

Aqui estabeleceu-se uma relação entre a ociosidade das vagas e a nota mínima atribuída a cada curso, mostrando que quanto maior a nota mínima, maior a ociosidade. Isso significa que quanto mais elevada essa nota, menos pessoas com deficiência conseguem alcançá-la e, portanto, mais vagas não são preenchidas.

Como as notas mínimas são de decisão dos colegiados diretores de cada curso, ao não se possuir estudos sobre os efeitos do estabelecimento dessas notas, pode-se incorrer em erros. O desconhecimento dos critérios ou do grau de discriminação das provas do Enem ou da Teoria de Resposta ao Item também induzem à tomada de decisão errada.

Talvez se possa afirmar ainda que a atual proposta da nota mínima fere o princípio da Lei de Cotas, pois restringe o acesso dos alunos aos cursos superiores sem nenhum embasamento pedagógico.

\section{REFERÊNCIAS}

BRASIL. Decreto no 7.824, de 11 de outubro de 2012. 2012. Disponível em: <http://www.planalto.gov.br/ccivil03/ato2011-2014/2012/decreto/d7824.htm>. Acesso em: 26/04/2021.

BRASIL. Lei no 12.711, de 29 de agosto de 2012. 2012. Disponível em: <http://www.planalto.gov.br/ccivil03/ato2011-2014/2012/lei/l12711.htm>. Acesso em: 26/04/2021.

Lei no 13.146, de 6 de julho de 2015. 2015. Disponível em: <http://www.planalto.gov.br/ccivil03/ato2015-2018/2015/lei//13146.htm>. Acesso em: 27/04/2021.

Lei no 13.406, de 26 de dezembro de 2016. 2016. Disponível em: <http://www.planalto.gov.br/ccivil03/ato2015-2018/2016/lei/l13406.htm>. Acesso em: 27/04/2021.

ESDRAS, D.; GALASSO, B. Panorama da Educação de Surdos no Brasil - Ensino Superior. Rio de Janeiro: Instituto Nacional de Educação de Surdos - INES, 2017.

INSTITUTO BRASILEIRO DE GEOGRAFIA E ESTATÍSTICA. IBGE. Censo Demográfico. 2010. Disponível em: <https://www.ibge.gov.br/estatisticas/sociais/populacao/9662-censodemografico-2010.html?edicao=9749\&t=destaques $>$. Acesso em: 26/04/2021.

INSTITUTO NACIONAL DE ESTUDOS E PESQUISAS EDUCACIONAIS ANÍSIO TEIXEIRA. INEP. O que é TRI? 2011. Disponível em: <http://portal.inep.gov.br/artigo//asset publisher/B4AQV9zFY7Bv/content/o-que-e-tri/21206>. Acesso em: 8/05/2021.

Mais de $\mathbf{5 0}$ mil participantes farão o Enem com recursos de acessibilidade.

2019. Disponível em: <http://portal.mec.gov.br/pronatec/oferta-voluntaria/418noticias/enem-946573306/79891-mais-de-50-mil-participantes-farao-o-enem-comrecursos-de-acessibilidade>. Acesso em: 26/04/2021. 
Edital no 27, de 30 de março de 2020. 2020. Disponível em: <https://www.gov.br/inep/pt-br/centrais-de-conteudo/legislacao/enem>. Acesso em: 26/04/2021.

Histórico do Enem. 2020. Disponível em: <https://www.gov.br/inep/pt-br/areasde-atuacao/avaliacao-e-exames-educacionais/enem/historico >. Acesso em: 26/04/2021.

Portaria no 458, de 5 de maio de 2020. 2020. Disponível em: <https://www.gov.br/inep/pt-br/centrais-de-conteudo/legislacao/enem>. Acesso em: 26/04/2021.

JUNQUEIRA, R.; MARTINS, D.; LACERDA, C. Política de Acessibilidade e Exame Nacional do Ensino Médio (Enem). Educ. Soc., Campinas, v. 38, n. 139, p.453-471, abr.-jun., 2017.

LERIA, L.; BENITEZ, P.: FERREIRA, L.; FRAGA, F. O Acesso do Estudante com Deficiência Visual à Educação Superior: Análise dos Microdados do Exame Nacional do Ensino Médio (Enem). Scielo Preprints, p. 1-25, mar./abr/ 2021.

OLIVEIRA, C.; BARWALDT, R.; LUCCA G. Análise do Desempenho de Pessoas com Deficiência que Prestaram o Exame Nacional do Ensino Médio - Enem. Tear: Revista de Educação Ciência e Tecnologia, v.9, n.1, p. 1-17, 2020.

PEREIRA, C. Políticas públicas de inclusão: desafios e benefícios da implementação da política de cotas para deficientes nas universidades federais. ECCOM, Lorena, v. 11, n. 21, p.179-188, jan./jun. 2020.

SISU. Relatórios. 2020. Disponível em: <https://sisu.mec.gov.br/\#/relatorio\#onepage>. Acesso em: 27/04/2021.

UNIVERSIDADE FEDERAL DO ESTADO DO RIO DE JANEIRO. UNIRIO. Resolução n 5.227 de 29 de outubro de 2019. Disponível em: <http://www.unirio.br/prograd/normatizacaoacademica/resolucoes/copy3_of_Res.5.22729.10.2019AdreferendumClculodasnotasdoEN EMdoscandidatosoriundosdoSISU.pdf>. Acesso em: 8/04/2021.

UNIVERSIDADE FEDERAL DO RIO GRANDE DO NORTE. UFRN. Resolução no 137/2021 - CONSEPE, de 09 de fevereiro de 2021.

\section{IN SISU, RESERVED SEATS FOR PEOPLE WITH DISABILITIES IN ENGINEERING ARE NOT FILLED UP. WHY?}

Abstract: The publication of Law No. 12,711 celebrates ten years in 2022. According to its 7th article, a revision of the access of black, indigenous, and disabled students in reserved seats will be promoted. Thus, the study of unfilled seats for people with disabilities is an urgent matter for decision-making during the revision of the Law. This article analyzes the data available in SISU for the first semester of 2020, the second semester of 2020, and the first semester of 2021, aiming to establish a profile of unfilled seats. Also, this paper focuses on the possible causes of the unfulfillment in reserved seats of Engineering courses for people with disabilities in Higher Education. The seats were illustrated as a function of the populations of the Brazilian states', regions, and type of institution. The available seats and 
the vacant seats in the three semesters were compared and a correlation was established between the increase in the minimum grade and the increase of unfilled seats, revealing that the percentage of vacant seats is proportional to the variation of the minimum grade.

Keywords: Engineering; Quotas; Person with disability; Enem; Sisu 